\title{
A better deal for newborns with congenital heart disease
}

Despite the great strides made in management of heart diseases in children during the last 25 years, these still account for more deaths in infancy than all other congenital anomalies put together. ${ }^{1,2}$ Furthermore in population studies on necropsy, it has repeatedly been shown that of deaths certified as due to congenital heart disease, about two-thirds were within the first year of life and about half of these were during the first month. ${ }^{3}$ Population necropsy studies tend to present a gloomier prognosis than those based on diagnosis in life as well death. Nevertheless, in a study of the latter type carried out as recently as 1968-72, it was shown that, even when patients with severe associated congenital lesions were excluded, only $61 \%$ of infants with congenital heart disease survived the first year. ${ }^{4}$ Effective prevention of congenital heart disease seems unlikely to emerge within the next decade, so that any policy designed to reduce death and disability from congenital heart disease must at present be focused on management during the early months of life. The paper by Izukawa et al. ${ }^{5}$ (page 281) documents in a heartening manner the improvement in life expectancy that has occurred in newborns with structural heart disease in the last decade treated at their hospital, which acts as a referral centre for a large part of Canada.

In a number of committee reports on resources for management of heart disease in children, the principle has been accepted that in order to provide optimal standards of care, a limited number of specialist centres are required. ${ }^{6,7,8,9} \mathrm{~A}$ revised report of the Joint Cardiology Committee is about to be published, taking the same view. This annotation will summarise the evidence supporting this view, and argue that in order to provide the best service for newborn babies with congenital heart disease, it is necessary to think in terms of creation of supraregional centres specialising in the care not just of newborns, but also of infants.

The reasons for the improvement in survival of newborns from Toronto ${ }^{5}$ are, in brief, experience and expertise. While these do not always go together, they usually do. Particularly strong evidence for this assertion comes from a study carried out in London during the period 1969-71 of centres treating infants with congenital heart disease. ${ }^{10} 13$ such centres were identified as being involved in infant cardiac catheterisation and surgery; 2 of these performed $69 \%$ of all cardiac catheterisations and $76 \%$ of all operations. The combined operative survival for infants from the 2 centres was $72 \%$, whereas the corresponding figure for the remaining 11 was $54 \%(\mathrm{P}<0.001)$. Furthermore, patients in the 2 centres were less likely to die at cardiac catheterisation, and more likely to have a corrective than a palliative operation. And this was despite the fact that both centres were seeing a population of infants with more serious congenital heart disease than were the others. So expertise is fundamental, but experience and therefore size cannot be ignored in planning cardiological services.

The incidence and severity of congenital heart defects is similar in America and England.11,12 Therefore the size of the British problem can be defined very precisely from the New England Regional Infant Cardiac Program. ${ }^{13}$ Case finding in that study ${ }^{14}$ is almost certainly higher than that from any comparable British study. In New England there is a mixture of units, some aggressive and some more conservative in their management, much as there is in this country, so that projections of work load from their experience are probably quite reasonable for the UK.

The number of live births in England and Wales in 1974 was 603 140. A survey of 16 centres in England and Wales carrying out infant cardiac catheterisations showed that $47 \%$ of these were in neonates. ${ }^{15}$ To these facts are added the following from the New England study:4,13,14

(1) The incidence of heart disease presenting in infancy and requiring cardiac catheterisation (2.7 per 1000) (D. C. Fyler, 1978, personal communication).

(2) The proportion of infants catheterised requiring operation in infancy $(58 \%)$.

(3) The proportion of infants with severe associated anomalies precluding cardiac surgical intervention $(10 \%)$.

From these figures it appears that each year 1470 (29.4 per million population) infant cardiac catheterisations and 850 infant operations can be expected from England and Wales. About 425 (8.5 per million) of these operations would be open heart ones. 
The number of neonatal catheterisations is a very reliable indicator of patients referred, since essentially all catheterisations in this age range are emergencies, carried out in seriously ill babies. This number, predicted from the above figures, is 690 (13.8 per million) per annum for England and Wales. In the British survey, ${ }^{15} 16$ major centres reported an average of 365 neonatal catheterisations per year (1971-75). One large centre reported a further 54, too late for inclusion, but it is difficult to believe that the overall total from every centre in England and Wales could exceed 500 per annum. This leaves the total figure still 190 short of the prediction. This large shortfall can hardly be accounted for by the fall in birth rate, particularly as the total number of catheterisations performed did not change during the survey period. Nor does it seem likely that the problem lies in applying American figures to British patients. The possibility must be faced that about $25 \%$ of neonates with congenital heart disease in this country are still being neither adequately investigated nor treated. Why should this be? The most likely answer is that there is insufficient awareness of the possibilities of effective, curative treatment in specialist centres.

Let us leave aside the question of shortfall, and assume that there is none for the purpose of determining how many specialist centres are required. Successful management of infants with serious congenital heart disease is a matter of highly coordinated team work involving technical staff, specially trained children's nurses, experts in anaesthetics, ventilation, radiology, and nephrology, as well as paediatric cardiologists and cardiac surgeons. At any level, lack of sufficient experience prejudices the outcome. It may well be that no centre in the UK has yet reached an optimal level of activity. However, a minimum is probably one infant open heart operation per week on average. Open heart surgery is chosen as the paradigm because it is the most demanding on personnel. To achieve the predicted requirements, only 8 centres in England and Wales would be necessary. However, two surgeons per centre are required to maintain 24hour cover. Sharing the work load, each would only do one infant open heart operation a fortnight. Most surgeons would not regard this as adequate to maintain standards, so the optimal number of centres required in England and Wales is probably less than 8 , particularly as these figures have been calculated for predicted rather than actual work load.

Supraregional centres along the lines proposed would not, of course, limit their activities to infants. If they were to do so, there would be an insufficient total volume of work, and what work there was would be of such complexity that it would make impossible demands on the personnel of such a unit. A much wider age range of patients would be treated.

This figure for the number of supraregional centres required is uncomfortably low, and specialisation of this order would undoubtedly introduce new problems. What are they, and would they outweigh the benefits?

The first disadvantage is of course that there would be a lot of travelling for the baby and relatives. This will never be a pleasant experience, but then neither is the unnecessary death of the baby. We (and doubtless others) have found that it is possible for a young infant to suffer several cardiac arrests outside the UK, and yet to survive a long air flight and corrective surgery in this country. This illustrates graphically that transport need not be hazardous provided that the means to maintain thermal, fluid, and acid-base balance, together with ventilation (if necessary), are initiated before the journey.

At the moment, such care is undertaken by the referring nonspecialist hospital. In the future, the responsibility for this kind of action may come to rest with the specialist centres, along the lines developed by general neonatal intensive care units. ${ }^{16,17}$ But because of the far greater distances, this would place demands upon the medical and nursing personnel in the specialist centres that would be extremely heavy, and certainly beyond the present capabilities of any unit of this type in the country.

Of particular concern, as so many of these emergencies occur in the first few days of life, is that the baby may be transported, but the mother is not. This inevitably impairs primary bonding and establishment of breast feeding. This is perhaps particularly unfortunate if the physical condition of the baby turns out not to be serious. These problems would, in my view, be greatly alleviated by a 2pronged strategy. Firstly, paediatric cardiologists would have to take more seriously their educational role with regard to budding (or even not so budding) paediatricians and neonatologists, as these play such a vital role in screening for serious structural heart disease. This would not only reduce unnecessary referrals (which are in any case rare), but, more importantly, help to ensure earlier referral of serious heart disease before the baby's condition becomes critical. Secondly, mothers could be encouraged more often to accompany their babies (particularly if they have no other children) and would be actively helped to do so, even if it meant extra medical care for the mother.

Cardiac catheterisation and surgery are not cheap when viewed in isolation, but there can hardly be another specialty where such sick individuals are so 
completely restored to normality for such a long time. So the cost-benefit ratio, insofar as this can be quantified, is probably low compared with many other widely performed procedures. All in all, the benefits of supraregionalisation of infant cardiac care far outweigh the disadvantages, provided that the latter are minimised along the lines suggested.

It is true that in 1979, now that some lesions can be repaired in infancy with an immediate survival of better than $95 \%$ in a few centres, that the residual problems are becoming more and more concentrated in the first month of life. ${ }^{18}$ But for three reasons, my view is that it would be a mistake at this stage to create neonatal rather than infant supraregional centres. Firstly, the number would be too small. Secondly, open heart surgery in later infancy is still far from routine even in specialist centres. Thirdly, some of the numerically most important conditions causing serious cardiac disability and death in infancy do not normally present until the 2 nd and 3 rd month of life, notably ventricular septal defect. Since it has been clearly shown that in certain centres, primary closure of the defect in infants with intractable cardiac failure carries a lower early and late mortality than banding of the pulmonary artery, ${ }^{19,20}$ there seems to be a good argument for the creation of centres where such open heart approaches to treatment may become routine. At this time, only a few such hospitals in this country have established reputations in the field, so that recognising these as supraregional centres would not be difficult. The longer action along these lines is delayed, the more centres will become involved. Rationalisation could then become painful to the point at which it would never happen. The arguments put forward will perhaps have convinced even the sceptical that this would be a pity.

\section{References}

${ }^{1}$ Menashe, V. D., Osterud, H. T., and Griswold, H. E. (1967). Mortality from congenital cardiovascular disease in Oregon. Pediatrics, 40, 334-344.

${ }^{2}$ Department of Health and Social Security (1970). Confidential Enquiry into Postneonatal Deaths 1964-1966. Reports on Public Health and Medical Subjects No. 125. HMSO: London.

${ }^{3}$ Hoffman, J. I. E. (1968). Natural history of congenital heart disease. Problems in its assessment, with special reference to ventricular septal defects. Circulation, 37, 97-125.

${ }^{4}$ Greenwood, R. D., Rosenthal, A., Parisi, L., Fyler, D. C., and Nadas, A. S. (1975). Extracardiac abnormalities in infants with congenital heart disease. Pediatrics, 55, 485492.

${ }^{5}$ Izukawa, T., Mulholland, H. C., Rowe, R. D., Cook, D. H., Bloom, K. R., Trusler, G. A., Williams, W. G., and
Chance, G. W. (1979). Structural heart disease in the newborn. Changing profile: comparison of 1975 and 1965. Archives of Disease in Childhood, 54, 281-285.

${ }^{6}$ Royal College of Physicians of London and Royal College of Surgeons of England Joint Cardiology Committee (1967). A Combined Medical and Surgical Unit for Cardiac Surgery. The Colleges: London.

${ }^{7}$ Court, S. D. M., and Jackson, A. D. M. (1972). Paediatrics in the Seventies. Oxford University Press: London.

${ }^{8}$ Scannell, J. G., Brown, G. E., Buckley, M. J., Ebert, P. A., Laufman, H., Rackley, C. E., Sabiston, D. C., Jr, and Sloane, H. E. (1975). Report of the intersociety commission for heart disease resources. Optimal resources for cardiac surgery. Guidelines for program planning and evaluation. American Journal of Cardiology, 36, 836-848.

${ }^{9}$ Programme Planning Group of the Scottish Health Service Planning Council (1977). Patterns for Health Services in Scotland: Cardiac Surgery. Scottish Home and Health Department.

${ }^{10}$ Robinson, J. (1972). Infant cardiac catheterisation in London 1969-1971. MSc thesis, London University.

${ }^{11}$ Mitchell, S. C., Korones, S. B., and Berendes, H. W. (1971). Congenital heart disease in 56,109 births. Incidence and natural history. Circulation, 43, 323-332.

${ }^{12}$ Kenna, A. P., Smithells, R. W., and Fielding, D. W. (1975). Congenital heart disease in Liverpool: 1960-1969. Quarterly Journal of Medicine, 44, 17-44.

${ }^{13}$ Fyler, D. C., Parisi, L., and Berman, M. A. (1972). The regionalisation of infant cardiac care in New England. Cardiovascular Clinics, 4, No. 3, 339-356.

${ }^{14}$ Rothman, K. J., and Fyler, D. C. (1976). Sex, birth order, and maternal age: characteristics of infants with congenital heart defects. American Journal of Epidemiology, 104, 527-534.

${ }^{15}$ Joint Committee on Higher Medical Training and Joint Committee on Higher Surgical Training (1977). Recommendations for the training of paediatric cardiologists and paediatric cardiac surgeons, by the sub-committee of the Specialist Advisory Committee on Cardiovascular Disease, the Specialist Advisory Committee on Paediatrics of the JCHMT, and the Specialist Advisory Committee on Thoracic Surgery of the JCHST.

${ }^{16}$ Storrs, C. N., and Taylor, M. R. H. (1970). Transport of sick newborn babies. British Medical Journal, 3, 328-332.

${ }^{17}$ Blake, A. M., McIntosh, M., Reynolds, E. O. R., and St Andrew, D. (1975). Transport of newborn infants for intensive care. British Medical Journal, 4, 13-17.

${ }^{18}$ Stark, J., de Leval, M., Macartney, F., and Taylor, J. F. N. (1979). Open heart surgery in the first months of life. In Cardiology: Proceedings of the Eighth World Congress 1978. Edited by S. Hayase. Excerpta Medica: Amsterdam.

${ }^{19}$ Blackstone, E. H., Kirklin, J. W., Bradley, E. L., Du Shane, J. W., and Appelbaum, A. (1976). Optimal age and results in repair of large ventricular septal defects. Journal of Thoracic and Cardiovascular Surgery, 72, 661-679.

${ }^{20}$ McNicholas, K., de Leval, M., Stark, J., Taylor, J. F. N., and Macartney, F. J. (1979). Surgical treatment of ventricular septal defect in infancy. Primary repair versus banding of the pulmonary artery and later repair. British Heart Journal, 41, 133-138.

Fergus MACARTNeY Institute of Child Health, Guilford Street, London WCIN 1EH 